\title{
LE CHEVALIER DÉLIBÉRÉ DE OLIVIER DE LA MARCHE TRADUCIDO POR ACUÑA: POESÍA Y EMBLEMÁTICA
}

\author{
OLIVIER DE LA MARCHE'S LE CHEVALIER DÉLIBÉRÉ TRANSLATED \\ BY ACUÑA: POETRY AND EMBLEMATICS
}

Marcial Rubio Árquez

Università degli Studi «G. d'Annunzio» di Chieti-Pescara

ABSTRACT: If in the French original of Le Chevalier délibéré one can appreciate the intimate relationship between the poetic text and the gorgeous engravings that accompany and illustrate it, in the tranlated version of Acuña this association is even stronger, to the point that one might say that the translator not only translates the French text linguistically, but also the book's images. This results then in a fusion between text and images that points clearly towards an emblematic vision in the book.

KEYWORDS: Hernando de Acuña, Le Chevalier délibéré, Emblematics, Translation.

RESUMEN: Si en la edición original francesa de Le Chevalier délibéré se aprecia una íntima relación entre el texto poético y los bellísimos grabados que lo acompañan e ilustran, en la versión de Acuña esta asociación se hace todavía más fuerte, hasta el punto que bien pudiera decirse que el traductor no solo traslada lingüísticamente el texto francés, sino también las imágenes del mismo. Se produce así una fusión entre texto e imágenes que apunta claramente a una visión emblématica del libro.

PALABRAS CLAVES: Hernando de Acuña, Le Chevalier délibéré, emblemática, traducción. 
Si en los orígenes de la cultura, la letra y la imagen anduvieron juntas, el siglo XVI fomentó la dialéctica entre ambas y creó una ilusión de correspondencias que apelaba además a la relación armónica tradicional entre el macrocosmos y el microcosmos.

Sirva la autoridad de Aurora Egido (1985: 8) para introducir un trabajo que, conviene precisarlo ya desde el inicio, quizás pueda resultar un tanto extraño a los estudios sobre la emblemática. Y es que, en efecto, el famosísimo libro de Olivier de la Marche Le Chevalier délibéré no es un libro de emblemas, o no lo es sensu stricto. Sin embargo, como intento demostrar en las siguientes páginas, comparte con la emblemática -o con una cierta manera de concebir y desarrollar la emblemática- bastantes elementos y características que son las que interesan si no analizar, dada la brevedad del trabajo, sí señalar en las páginas que siguen.

Si bien su autor murió al alborear el siglo XVI (1502), por tanto bastantes años antes de la genial invención de los editores de Alciato (1531), su formación intelectual, absolutamente adscrita a la corte borgoñona, uno de los centros de difusión cultural de una nueva "expresión simbólica» precursora en cierto sentido de la eclosión emblemática europea (Rodríguez de la Flor, 1995: 35), le convierte en precursor de algunos de los temas y recursos de gran parte de la literatura emblemática, y así es fácil encontrar en todas sus obras, pero particularmente en Le Chevalier délibéré, una "consideración ética» y un "tono moralizante», hermanados al uso proficuo de la "alegoría» y de la "experiencia humana» y, sobre todo, la fusión entre "ficción»y "moraleja» (Clavería,
1950: 11 y ss.), elementos característicos de toda o gran parte de la literatura emblemática. Si desde esta característica topográfica de su cultura profundizamos más y lo adscribimos -como ya hizo Clavería (1950: 14)- a la escuela de los "rhétoriqueurs», los elementos comunes de su obra con la emblemática son todavía más evidentes, pues, como nos recuerda el citado estudioso, la «obsesión didáctica» y la "representación plástica de los conceptos» son dos características primordiales de esta corriente literaria.

Le Chevalier Délibéré, escrito en 1483 tuvo, a juzgar por los manuscritos que conservamos -dieciocho, copiados entre los siglos XV y XVII-, un enorme éxito. ${ }^{1}$ La primera edición data de 1488 (Paris, Antoine Vérard $)^{2}$ y a partir de esa fecha cuenta con numerosas ediciones hasta la última del siglo XVI, en 1540, aunque esto no le impidió seguir circulando en forma manuscrita hasta $1873 .^{3}$

Ya desde los primeros manuscritos de finales del siglo XV, la inseparable unión de texto (subscriptio) e imagen (pictura), que podría definirse como una de las características de la emblemática desde su nacimiento, forma parte de la obra. En efecto, en la misma aparecen íntimamente asociados los versos del poema con bellas ilustraciones que intentan reproducir visualmente lo que en ellos alegóricamente se dice (Delen, 1923). Cuando del manuscrito se pasa a las primeras ediciones incunables, se sigue conservando, como no podía ser menos, esta intrínseca relación. Añádase, como quizá la prueba más decisiva de esta fusión texto/imagen, que conservamos las precisas instrucciones, quizás del propio de La Marche, sobre cómo debían realizarse las ilustraciones, ${ }^{4}$ lo que demuestra que, ya

1. El trabajo fundamental para los manuscritos y ediciones de la obra sigue siendo É. Picot y H. Stein (1923), que debe actualizarse ahora con la introducción de C. W. Carroll (1999: 14-28).

2. Hay una magnífica edición facsímil en Messerli $(2010)$, quien también reproduce la segunda edición conocida (Gouda, 1489) (Collaciebroeders, s.d.), y el manuscrito, Flandres, env. 1484.

3. Para la difusión de la obra en la Francia de los siglos XV y XVI, con especial atención a los destinatarios de la misma, se vea S. S. Sutch [2005-2006: 335-350].

4. Las edita Carroll (1999: 329-352) y también Messerli (2010: 483-492). 
desde su génesis, el autor planeaba un texto acompañado de imágenes. Incluso, yendo un poco más allá, se podría decir, dada la minuciosidad de las citadas instrucciones y el ambiente cultural en el que nació la obra, que de La Marche escribió su poema para acompañar estas imágenes tan vivas en su imaginación. En este sentido la obra se acerca indudablemente a la emblemática pues, como nos recuerda el magisterio de Aurora Egido (1985: 13):

[...] la palabra, colocada al pie de la pintura o describiéndola, genera, por su propia mecánica, un espacio y una dinámica diferentes que sólo una interpretación sinestésica del ut pictura poesis horaciano podría identificar con la del objeto artístico que recrea o suscribe.

La obra de De la Marche tuvo un más que discreto éxito en tierras castellanas, mereciendo dos traducciones: la de Jerónimo de Urrea en 1555 y la más temprana de Hernando de Acuña (1553) que es a la que dedicaré las siguientes páginas. ${ }^{5}$ No creo que haga falta presentar al traductor, Hernando de Acuña, brillante poeta de la primera generación de petrarquistas que dedicó gran parte de su labor poética precisamente a la traducción. Digo esto porque conviene ubicar el empeño de Acuña con la obra del francés dentro de unas coordenadas precisas, que no son las del traductor ocasional, sino las de un autor que ha experimentado ya el trabajo del traslado lingüístico en numerosas ocasiones, acometiendo obras como el Orlando innamorato de Ariosto, entre otras (Morelli, 1977; Rubio Árquez, 2011). Con esto quiero decir que la elección de Acuña no debió ser provocada sólo por su condición de cortesano o de poeta, sino, también y sobre todo, por su experiencia como traductor. Hablo de «elección» porque, aunque brevemente, quisiera romper una lanza a favor de la autoría de Acuña. En este sentido, el título del presente trabajo intenta ser una invitación a revisar ese fósil crítico que afirma que la traducción del libro de Olivier de La Marche es obra, a cuatro manos, de Carlos V y de Hernando de Acuña. El máximo defensor de esta teoría es, como se sabe, Clavería, quien manifestaba que "no parece imposible que Carlos fuera capaz de traducir, para distraerse, en prosa española una obra que conocía a fondo y había releído muchas veces" (Clavería, 1950: 65). Parecida opinión, siguiendo al estudio anterior, mantienen Baranda e Infantes (2000: 23 y ss.). Pese a todo, el único testimonio que avala dicha colaboración es la afirmación de Guillermo van Male quien afirmaba que:

Caesar maturat editionem libri, cui titulus erat gallicus: Le chevalier délibéré. Hunc per otium a se ipso traductum tradidit Ferdinando Acuñae Saxonis Custodi, ut ab eo aptaretur ad numeros rithmi hispani: quae res cecidit felicissime; Caesari sine dubio debetur primaria traductionis industria, non solum linguam, sed et carmen et vocum significantiam mire expresserit (1843: 15).

De van Male (Malineus en latín o Malínez para los españoles) sabemos que fue, sí, fiel servidor de su señor Carlos V, pero, también, algo exagerado cuando se trataba de enumerar las dotes literarias del mismo. Recordemos su bulo acerca de la escritura de mano del Emperador de las expediciones que este había hecho hasta 1550, manuscrito que, según van Male, obraba en su poder y que podía compararse en elegancia e historicidad a Tito Livio, a Suetonio, etc. por lo que pronto vería la luz. Como sabemos, el manuscrito de dicha obra nunca apareció, pese al interés que Felipe II puso en encontrarlo (Prescott, 1857: 364). Recordemos también que van Male era parte interesada en la edición de la obra, pues la edición de la traducción castellana corría a su costa,

5. Para las ediciones españolas son imprescindibles los trabajos de J. Peeters-Fontainas [1960: pp. 178-179] y ahora N. Baranda y V. Infantes [2000: 28-41].

IMAGO, NÚM. 5, 2013, III-118 
con lo que debió pensar que un poco de publicidad «imperial» no venía del todo mal. Estas y otras razones que podríamos aportar demuestran que el único dato que tenemos para afirmar dicha colaboración es más que dudoso, por lo que apoyamos el docto juicio emanado por Stein hace ya bastantes años (Picot y Stein, 1923: 339) sobre la autoría de la traducción. Otra cosa es, claro, que el Emperador animara a que el libro se tradujera, e incluso se puede aventurar que eligiera a Acuña para hacerlo por las circunstancias que ya hemos apuntado: era poeta y traductor y como tal era conocido en el séquito imperial.

Pero no es este el único equívoco que pervive en la crítica sobre este precioso libro. Hay otro que afirma que el manuscrito 1475 de la Biblioteca Nacional de Madrid, que reproduce también la traducción del texto, es copia de una de las ediciones anteriores -Amberes, 1553 o 1555 y que se preparó de cara a una nueva edición. Como espero publicar próximamente, el citado manuscrito es en realidad un apógrafo sobre el cual se preparó la primera edición, la de 1553. Por esta razón, mi estudio se basará en este manuscrito y no, como suele hacerse, en las ediciones impresas que, además y por lo que respecta a los grabados, no son ni demasiado fieles al original francés, ni tan bellas como los dibujos del manuscrito.

Como ya he dicho, y dejando de lado las pocas ediciones originales que no llevan ningún grabado, como, por ejemplo, la de Lyon, M. Havard, s. d., en Le Chevalier délibéré palabra e imagen van indisoluble y artísticamente juntas. Prueba de ello son las ya citadas "Instrucciones». Por ellas sabemos no sólo cómo debían ser los grabados, sino también su número y su posición en el texto. Así sabemos, por lo que respecta al primer dato, que debían ser quince, si bien el dígito no siempre se respeta en los textos franceses, ya sean manuscritos o impresos. En el texto manuscrito de la traducción castellana, sin embargo, los grabados con- servados son diecinueve, aunque originariamente debían ser veinte, habiendo sido arrancado el grabado que debería llevar el número cinco y que, seguramente, representaba al "Autor» cenando en el jardín con «Pensamiento». ¿Cómo se ha pasado de los quince grabados originales a los veinte castellanos? En primer lugar, se ha añadido un dibujo que no forma parte -como nos indican las «Instrucciones»-de los grabados originales, sino que es una reproducción de la portada de la segunda edición francesa, la de Gouda, 1489, sin duda la edición que, por lo que respecta a los grabados, presenta los de mayor belleza y fidelidad a las citadas instrucciones. El detalle es importante porque si no bastara la enorme semejanza entre los grabados del manuscrito castellano -y también los del resto de ediciones, que lo copian- y el de esta edición, el hecho de que se inserte en un lugar tan significativo como el del colofón del manuscrito parece aportar un indicio sobre qué texto francés se utilizó en la traducción. Los otros cuatro grabados que se añaden en el texto castellano representan la llegada de Isabel de Castilla, de Felipe el Hermoso, de Fernando el Católico y del Emperador Maximiliano, respectivamente, a la Corte del rey Átropos. Estos cuatro grabados son muy similares entre ellos y reproducen, con pequeñas variantes, el grabado número trece de las «Instrucciones» que representa, justamente, la llegada de la Archiduquesa de Austria a la Corte de Átropos. Como se ve, por tanto, el texto español no inventa cuatro nuevos grabados, sino imita o copia uno de la edición francesa adaptándolo a cuatro nuevos personajes.

Este cambio iconográfico comporta, evidentemente, algunas modificaciones textuales. Como ocurre casi siempre con la traducción renacentista y particularmente en el caso de Acuña, la labor de traslado lingüístico va más allá de la simple reproducción en una lengua de lo que, más o menos, se expresa en otra. En el caso que nos ocupa serían innumerables las aportaciones parti- 
culares que Acuña hace a la traducción del texto francés. Quizá la más importante es la que se produce al llegar a la estrofa 269 del texto francés, cuando "Armes Respit» el personaje que en la traducción española viene llamado «Plazo»- comunica al «Autor" que no es todavía el momento en el que deberá enfrentarse con los caballeros de «Átropos», «Debilidad» y «Accidente» o, en otras palabras, que todavía no ha llegado la hora de su muerte. El texto francés luego hace que "Fresche Memoire» cuente al "Autor» el trágico fin de los duques borgoñones, esto es, Felipe de Borgoña (Felipe III el Bueno, muerto en 1467) -estrofas 219-235-, Carlos I el Temerario (muerto en la batalla de Nancy en 1477) -estrofas 236255- y de María de Borgoña, hija del anterior fallecida en 1482 -estrofas 256-267-. Obsérvese que esta fecha es muy próxima a la escritura de Le Chevalier délibéré que, como hemos visto, se terminó sólo un año después, en 1483. En este sentido, y el dato es importante por lo que veremos a continuación, la obra de de La Marche es el canto póstumo a la casa de los Duques de Borgoña, a los que el autor dedicó toda su vida y, también, su obra literaria. Para el francés, con la muerte de María termina una época y acaba, por las mismas razones, un cierto modo de entender el mundo: el de la cultura borgoñona.

Pues bien, Acuña, con gran sagacidad, supo ver que allí donde terminaba para el francés una época, comenzaba para el mundo hispánico otra. Se deja ver ya en la utilización de los tiempos verbales: allí donde el francés utiliza los tiempos de pasado y presente, Acuña utilizará presentes y futuros. En efecto, de La Marche cuenta lo que pasó -lo que históricamente ya ha pasado cuando él escribe-, mientras que Acuña -a través de ese personaje emblemático denominado «Plazo»- narra lo que va a pasar por más que, como en el francés, cronológicamente, históricamente ya haya pasado. Sobre esto volveré después. Ahora me interesa señalar la larga serie de coplas -de la 229 a la 315, más de 86- en las que, por decirlo así, hispaniza, y no sólo por la lengua utilizada, el relato, sometiéndolo a una estructura bien precisa que es la que pretendo analizar.

La adición se articula narrativamente en torno a cuatro personajes que aparecen en el relato con un orden cronológico perfecto, paralelo al utilizado por Olivier pero con otra clara significación: Isabel de Castilla $(† 1504)$, Felipe el Hermoso (†1506), Fernando el Católico (†1516) y Maximiliano de Austria (†1519), respectivamente. Cada personaje, al que se le dedican entre 13 y 19 coplas $-^{6}$ viene acompañado por una representación gráfica, tal y como ocurría en el texto francés. Lo curioso es que en el texto original los respectivos grabados representaban a los dos personajes aludidos (Felipe y Carlos) combatiendo, mientras que, por el contrario, al último, María de Borgoña, se le representa en el momento de llegar a la Corte de Átropos. El texto francés después es coherente y, en efecto, mientras que con los dos personajes masculinos se nos describe el combate y posterior derrota o muerte, con María se narra más su entrada triunfal que su trágico fin, resuelto con un escueto «il la blessa alors subitement / d'un jet de fièvres incessant» (est. 262).

Acuña, como ya demostró Clavería, percibe e imita perfectamente el tono de estos singulares combates con la muerte y los reproduce, en su parte original, con excepcional maestría. Quizá él mismo o quizás el librero-editor, justamente para continuar este paralelismo perfecto entre el texto original y la versión castellana añadida, decide insertar un dibujo por cada uno de los personajes, tal y como se hacía en el texto francés. Lo curioso es que, con independencia del personaje y del tipo de derrota que le infrinja Átropos, todos los dibujos tienden

6. Isabel de Castilla, coplas 237-252; Felipe el Hermoso, 253-266; Fernando el Católico, 267-283 y Maximiliano de Austria 284-303. 
a imitar el de María de Borgoña, es decir, se representa la llegada del personaje en cuestión a la corte de Átropos y no el combate con sus dos terribles caballeros, como ocurre frecuentemente en el texto original. Veámoslo con más detalle en el primer ejemplo. La primera en aparecer, como ya he dicho, es Isabel de Castilla. A ella se le dedican las coplas 237-252. Como es preceptivo, con la aparición del primer personaje español, se hace una verdadera laudes hispaniae:

Ya sabrás que en Occidente España es reino famoso, Por todo generalmente, Y en especial poderoso Por el valor de su gente. ${ }^{7}$

El tono con el que se abre el añadido de Acuña es fundamental ya que, como veremos, marca la intencionalidad del mismo.

La representación de Isabel, por tanto, imita la de María, pero con la diferencia de que después, en el texto, se nos narra el cruel combate entre "Accidente» y la reina de Castilla (coplas 245-251). Por lo que respecta a los aspectos gráficos, quizás los cambios más significativos sean que "Accidente» no aparece en el ángulo superior derecho en el momento de ser armado por sus pajes, como ocurría en el grabado francés, sino ya armado y esperando amenazador la llegada de la reina en el margen derecho del dibujo. Su puesto lo ocupan ahora, con una posición más relevante que viene dada por un mayor tamaño, el «Autor», la «Memoria» y el "Plazo», representado en el mismo acto de contar lo que va a suceder.

El segundo personaje de la inserción original de Acuña es, como ya se ha dicho, Felipe el Hermoso, al que se le dedican las coplas 253-266. Desde los primeros versos, Acuña está interesado en explicar los motivos de la inclusión de este personaje:
Y será este aventurero,

De Austria y Borgoña heredero,

Hierno de esta gran señora

Cuyo paso conté agora,

Doloroso y lastimero.

Por quien se vendrá a juntar

Con las dos casas que cuento

Castilla, do irá a reinar

Mediante este casamiento

Príncipe tan singular. ${ }^{8}$

En efecto, con Felipe I de Habsburgo, hijo del emperador Maximiliano -que aparecerá después- y de María de Borgoña, hija de Carlos el Temerario, último duque de Borgoña, la historia vuelve a las raíces, tanto cronológicas como -y esto es lo más importante- narrativas, ya que el añadido de Acuña establece una relación clara con el texto francés. La diferencia, claro está, es que se dispara hacia el futuro al ser Felipe I el padre de Carlos V. El dibujo, como ya se ha indicado, imita en gran manera al de Isabel, con la única diferencia de que «Memoria», el "Autor» y el «Plazo», que antes figuraban a la izquierda, ahora lo hacen a la derecha, dejando así su sitio para el torno de "Átropos».

Conviene decir que tanto a Isabel como a Felipe les vence uno de los caballeros de Átropos, concretamente "Accidente», mientras que a Fernando el Católico -el tercer personaje- le derrota «Debilidad». Este detalle parece aludir a los motivos reales de la muerte de estos personajes, claros en el caso de la temprana muerte de Felipe -murió a los 28 años-, pero no tanto en el de Isabel, que vivió hasta los 53. Quizás con ello Acuña esté haciendo referencia a las continuas desgracias que acosaron la vida de la reina de Castilla en sus últimos años, con la muerte de su único hijo varón, la locura de su hija, la actitud de Felipe, etc., como si fueran estos "accidentes», y no el cáncer, 
los verdaderos causantes de su muerte. A Fernando de Aragón, por el contario, que vivió hasta los 64 años, es lógico que se le represente vencido por la «Debilidad».

Esto nos sirve para enlazar con el último personaje que Acuña introduce en su adición. Se trata del emperador Maximiliano de Austria. Digo que sirve de nexo porque contra el Habsburgo deberán combatir, para lograr vencerlo, tanto «Debilidad» como "Accidente». Su presentación también parece un guiño a la política imperial defendida por Acuña:

Que este es al que más temieron Venecianos poderosos,

Con quien Bohemios perdieron

Y Franceses belicosos

Rotos y deshechos fueron. ${ }^{9}$

El dibujo que acompaña el texto, por su parte, imitando siempre el modelo francés de la llegada a la "Corte de Átropos", cambia de nuevo a los personajes, apareciendo "Memoria», "Plazo» y el "Autor» a la izquierda y "Átropos» a la derecha.

He intentado explicar cómo la traducción de Acuña va más allá del simple traslado lingüístico. Se trata, como evidencia la adición en la que me he detenido, de hispanizar el texto haciendo de él una continuación lógica, genealógica y, en cierto sentido, cronológica del texto francés. Si de La Marche acaba su libro con María de Austria, es lógico que Acuña lo haga con su esposo, el emperador Maximiliano, no sin antes, claro está, pasar por los fundadores de la dinastía castellano-aragonesa, que además sirven de nexo, como él mismo indica, entre los reinos españoles y la casa de Borgoña a través de Felipe el Hermoso. Lo curioso es que, como sabemos, el texto original se formó en una corte borgoñona cuyos protagonistas eran los tres antes aludidos, María, Maximiliano y Felipe. La supuesta omisión de La
Marche no es tal si se recuerda que, tras la muerte de Carlos el Temerario el ducado de Borgoña debía pasar a manos del rey francés, Luis XI, con lo que dicha dinastía, como bien señala el autor, desaparecía para siempre. Lo que hace Acuña con su adición es recordar que no es así, que el glorioso ducado, precisamente con la boda del último personaje que enumera La Marche, con el último de los suyos, Maximiliano, conocerá un nuevo esplendor -ahora bajo la casa de los Habsburgo- primero con Felipe el Hermoso y, sobre todo, con Carlos V. Es aquí donde se puede adivinar la mano de Carlos $\mathrm{V}$, acérrimo lector del texto francés, al que es fácil imaginar decepcionado por la lectura de un libro que, si bien cantaba las glorias pasadas de sus antecesores, no pudiendo llegar hasta su presente, omitía que el final no era el cantado por de La Marche, triste y desolado, sino otro mucho más glorioso que el pasado, con un borgoñón al mando de un Imperio, y recuérdese que Carlos V tuvo que renunciar al territorio de Borgoña por la paz de Cambrai (1529) pero jamás perdió el título de Duque de Borgoña. Los dibujos de la parte añadida, por último, reproducen emblemáticamente este triunfo, al representar todos el momento glorioso, digno, elocuente, de la entrada de los personajes en la Corte de Átropos, no su derrota, pues, por lo dicho, se entenderá que se trata ahora, en la versión española, de un paso obligado de todo ser humano y no, como en el francés, del declive de una estirpe.

\section{BIBLIOGRAFÍA}

Baranda N. y V. Infantes, [2000]. "Un libro para el Emperador", en El Caballero determinado de Olivier de la Marche traducido del francés por Hernando de Acuña, Toledo, Antonio Pareja editor, 7-44.

9. Est. 286, vv. 1-5, f. 100 mss. 
Carroll, C. W., ED. [1999]. Olivier de La Marche, Le chevalier délibéré. The Resolute Knight, Edited by Carleton W. Carroll; Translated by Lois Hawley Wilson and Carleton W. Carroll, Tempe, Arizona Center for Medieval and Renaissance Studies (Medieval and Renaissance Texts and Studies, 199).

Clavería, C. [1950]. "Le chevalier délibéré» de Olivier de la Marche y sus versiones españolas del siglo XVI», Zaragoza: Institución "Fernando el Católico".

Delen, A.J.J. [1923]. «De Illustraties van 'Le Chevalier délibéré'», Het Boek 12, 22532, después reimpreso, por donde se cita, en Oude Vlaamsche graphiek: studies en aanteekeningen, Antwerpen, Het Kompas, 1943, 24-34.

EgIdo, A. [1985]. "Prólogo» a Alciato, Emblemas, ed. Santiago Sebastián, Madrid, Akal, 7-17.

Messerli, S., ED. [2010]. Olivier de la Marche, Le chevalier délibéré. Introduction et traduction de..., París, Presses Universitaires de France, 2010.

Morelli, G. [1977]. Hernando de Acuña. Un petrarchista dell'época imperiale, Parma, Università degli Studi di Parma (Studium Parmense Editrice).

Peeters-Fontainas, J. [1960]. "Les éditions espagnoles du 'Chevalier délibéré' d'Olivier de La Marche», De Gulder Passer, 38, 178-179.
Picot, É. y Stein, H. [1923]. "Le Chevalier délibéré par Olivier de la Marche. Schiedam vers 1498", Recueil de pièces historiques imprimées sous le règne de Louis XI reproduites en fac-similé. Texte, Paris, Sociétè des Bibliophiles François, 322-339.

Prescott, W. H. [1857]. Historia del reinado de Felipe segundo, Rey de España, Madrid, Est. Tip. De Mellado, 2 vols.

RodríGUEZ DE LA FLOR, F. [1995]. Emblemas. Lecturas de la imagen simbólica, Madrid, Alianza Editorial.

Rubio Árquez, M. [2011]. "Hernando de Acuña, traductor", en "Huir procuro el encarecimiento". La poesía de Hernando de Acuña, ed. de G. Cabello Porras e S. Pérez-Abadín Barro, Santiago de Compostela, Universidade de Santiago de Compostela, 2011, 277-317.

Sutch, S. S. [2005-2006]. "La réception du Chevalier délibéré d'Olivier de La Marche aux $\mathrm{XV}^{\mathrm{e}}$ et $\mathrm{XVI}^{\mathrm{e}}$ siècles", Le Moyen Français, 57-58, 335-350.

VAN MALE, G., [1843]. Lettres sur la vie intérieur de L'Empereur Charles Quint, écrites par Guillaume Van Male,gentilhomme de sa chambre et publiees, pour la premier fois par le baron Reiffenberg, Bruselas, Delevigne et Callewaert. 